\title{
El regreso de las abejas perdidas. Los niños salvajes en los límites de la cultura
}

\section{The Return of the Lost Bees: Wild Children in the Limits of the Culture}

\author{
María García Alonso \\ UNED. Madrid
}

\section{RESUMEN}

Los niños salvajes son una categoría de personas que tiene en común el haber pasado los primeros años de su vida en estado de aislamiento, entendiendo por aislamiento una situación en la que el individuo permanece sin compañía humana, aunque pueda convivir con otro tipo de animales sociales como lobos o monos. Este artículo plantea los principales modelos interpretativos sobre su existencia, que se han ido sucediendo a lo largo del tiempo, y que han convertido a estas criaturas en objetos privilegiados de la experimentación sobre los límites de la naturaleza humana y sobre los peligros de la cultura.

Palabras clave: Niños salvajes; Niños lobo; Estado de naturaleza; Salvajismo; Homo silvaticus; Homo ferus; Aislamiento cultural.

\section{SUMMARY}

Wild children are a category of persons that has in common to have passed the first years of their lives in isolation state, understanding by isolation a situation in which the individual remains without human company, although can coexist with another type of social animals like wolves or monkeys. This article explores the main interpretative models on their existence, that have been followed one another throughout the time, to transform these creatures in privileged objects of the experimentation on the limits of the human nature and on the dangers of culture.

Key Words: Wild children; Wolf children; Nature estate; Wildness; Homo silvaticus; Homo ferus; Cultural isolation. 
Echado al mundo sin fuerzas fisicas y sin ideas innatas, impedido para obedecer por si mismo a las propias leyes constitutivas de su organización que lo destinan, sin embargo, al primer puesto en la escala de los seres, solamente en el seno de la sociedad puede el hombre acceder al lugar eminente que le fue señalado en la naturaleza; sin la civilización jamás podría llegar a situarse sino entre los más débiles y menos inteligentes animales.

Jean Itard. 1801. Memoria acerca de los primeros progresos de Victor de L'Aveyron.

Los niños salvajes son una categoría de personas que tiene en común el haber pasado los primeros años de su vida en estado de aislamiento, entendiendo por aislamiento una situación en la que los individuos permanecen sin compañía humana - aunque puedan convivir con otro tipo de animales como lobos, osos o monos-, confinados o abandonados en soledad. Sin embargo, como señala Benzaquén, no es suficiente que se produzcan estas circunstancias para que sean denominados así.

El niño salvaje es siempre un niño extraño - percibido como extraño, imbuido de la cualidad de la extrañeza-, pero no se piensa que todos los niños extraños son niños salvajes. No hay una única razón para que un niño sea etiquetado o llamado salvaje, sino una serie de razones contingentes y a menudo extrínsecas, que tienen que ver con el contexto social, histórico e intelectual del tiempo en el que el niño apareció y con los motivos y las expectativas de los que, directa o retrospectivamente, etiquetaron u observaron al niño mucho más que algo que tuviera él en sí mismo. [...] Por ejemplo, Genie fue etiquetada como "niña salvaje" en 1970 en el contexto del estreno en Los Ángeles de la película de Truffaut El niño salvaje (sobre Víctor de Aveyron), debido al deseo de parte de los doctores y científicos que se encargaron del caso, de emular los logros de Itard, el maestro-médico de Víctor. El muchacho llamado "el salvaje de Drôme", no fue etiquetado "niño salvaje" en 1811, justamente en el momento en que Víctor, entonces un hombre, había sido "expulsado" del instituto de Sordomudos de París (Benzaquén 1999: 52-53).

Tanto en el caso de Genie ${ }^{1}$, como en el del salvaje de Drôme las opiniones no eran unánimes. La madre de Genie sintió como una ofensa el apelativo que se le dio a su hija que era para ella, simplemente, una joven con problemas. Del mismo modo el ministro francés de Interior había dado al muchacho de Drôme el mismo calificativo que a Víctor, pero el hospital

\footnotetext{
${ }^{1}$ Genie había sido encerrada por sus padres en una habitación durante al menos diez años en Temple City (California). Tenía trece años en el momento de su liberación. Estaba malnutrida y sus músculos atrofiados.
} 
que se había encargado de financiar los experimentos de Itard no podía permitir un nuevo fracaso por lo que este caso fue oscurecido y, al final, olvidado.

De este modo, para que la denominación prospere tiene que darse un cúmulo de factores entre los que destacan la oportunidad de la historia dentro de los intereses intelectuales o comerciales del entorno cercano al descubrimiento, y el ajuste de la misma al patrón narrativo que se espera de ella, lo que suele ocurrir indefectiblemente.

La información aportada por los que en algún momento son capaces de hablar sobre su existencia anterior es comúnmente vaga e imprecisa, como es lógico. La mayor parte de los hechos que los seres humanos conocemos de nuestra infancia han sido contados por testigos y aprendidos reflexivamente. Esos relatos van construyendo nuestra biografía de tal modo que acaban siendo contados en primera persona. Al no existir este referente en estos niños, que crecieron aislados, la única información disponible son los retazos que la memoria pueda ir reconstruyendo con un vocabulario mínimo: una combinación de olores, de texturas, de sonidos escuchados, de imágenes difícilmente transmisibles. ${ }^{2}$ Por ello suelen ser otros los encargados de desentrañar sus orígenes, atribuyéndoles un pasado acorde con las investigaciones que se estuvieran llevando a cabo con ellos como objeto o la tarea a la que se les destine. Y, ciertamente, las preguntas a las que responde su estudio han sido cambiantes a lo largo de los siglos, dependiendo de los presupuestos filosóficos y morales de las sociedades que los crearon.

Muchos son los nombres y las historias trágicas, que tienen como principales ingredientes el horror, la soledad y el abandono. Peter de Hamelin, amamantado por una osa, que vivió hasta una edad avanzada llegando a ser la más preciada posesión del rey de Inglaterra, su más divertido bufón; Memmie Le Blanc, la niña salvaje de Champagne, la Puella Campanica que daría nombre a toda una categoría de homines feri; Víctor de L'Aveyron, uno de los muchos niños perdidos a consecuencia de la Revolución Francesa y que debe su celebridad al interés de Jean Itard por sacarle del mundo del salvajismo y llevarle al de la cultura; Kaspar Hauser, encerrado en una habitación durante años con un caballo de madera, que pudo ser un noble escondido por problemas de sucesión y que moriría asesinado antes de que recordara su origen; Amala y Kamala, las niñas lobo de Midnapore, que eran los lobeznos más fieros, los que atacaron a sus libertadores con más saña cuando estos mataron a la loba que protegía a sus cachorros; Iván Mishukov,

\footnotetext{
${ }^{2}$ Por ejemplo, el único recuerdo exteriorizado del niño babuino, encontrado en Sudáfrica en 1904, fue la imagen de un gran avestruz que le golpeó el cráneo dejándole una deformidad perenne.
} 
el niño de los perros, que no había conocido mejor hogar que el que le proporcionaba la jauría callejera de la que se había convertido en jefe, cuando a los cuatro años huyera de una madre alcohólica. Y otros muchos, tantos que sólo pueden ser conocidos por la efímera noticia de sus hallazgos y la expectación que provocan en sus investigadores, sumiéndose posteriormente en el olvido cuando pasan de ser curiosidades naturales a adultos retrasados.

En la práctica, actualmente, no suele hacerse ninguna distinción entre los pequeños que llevaron una existencia solitaria pero en convivencia con animales y los que fueron encontrados recluidos en habitaciones en soledad absoluta. Ambos son considerados enfermos y se registran sus carencias motoras y sensitivas como si se tratara de cualquier otro discapacitado. Generan sobre todo problemas de índole legal en los que la búsqueda de los culpables y la determinación de la custodia plantean más inconvenientes que la propia enigmática condición de los pacientes. Pero en el pasado su presencia se situó en el vértice de polémicas radicales sobre la naturaleza humana.

Como los estudios sobre estos niños revelan mucho menos sobre la propia historia de los protagonistas que sobre los intereses culturales de los investigadores, las páginas siguientes hablarán de algunas teorías desarrolladas en esas investigaciones. No se trata de hacer un estado de la cuestión del problema, sino mostrar cómo los niños bravíos, que suman al imaginario sobre la vida salvaje la ambigüedad de su propia condición infantil, han sido una categoría sujeta a una constante redefinición por parte de los científicos, que han vuelto a ellos reiteradamente porque les han resultado útiles para reflexionar sobre distintos aspectos del mundo de la cultura y de la naturaleza.

Pueden distinguirse básicamente cuatro líneas de trabajo en el estudio de estas criaturas salvajes, que nos sirven para posicionarlos —más allá de su existencia real y doliente-, como modelos culturales que exploran los límites de la experiencia humana, las discontinuidades en el ordenado paisaje de las edades de la vida. La primera de ellas, más antigua en el tiempo, confronta su existencia con la de otros seres ambiguos: los homines silvatici, que constituyen en sí mismos un paradigma literario. La segunda — cuyos ejemplos más señalados serían Peter de Hamelin, encontrado en 1724, Memmie Le Blanc (1731), y Víctor de L'Aveyron (1799)_ explora las posibilidades (y las imposibilidades) de un estado de naturaleza previo al contrato social, en el que el individuo pudiera sobrevivir en soledad. En un tercer momento, el descubrimiento de Kaspar Hauser, hallado en Nuremberg en 1828 y, sobre todo, los estudios de Bettelheim después de la II Guerra Mundial sobre los niños autistas —incapaces de desarrollarse como indivi- 
duos por un sistemático proceso de castración de las emociones-, convierte su salvajismo en una paradójica consecuencia de la civilización. Los últimos estudios sobre estas criaturas se decantan por el análisis de los límites de la experimentación y sobre la ética de las investigaciones que con ellos se han llevado a cabo, es decir, sobre la interacción entre investigadores e investigados.

\section{LOS PEQUEÑOS HOMINES SILVATICI}

Si intentáramos realizar una "historia natural" de los niños salvajes tendríamos que comenzar remontándonos a los dioses clásicos —Zeus alimentado por la cabra Amaltea, por ejemplo- o a algunos héroes culturales que comienzan las dinastías como Rómulo y Remo ${ }^{3}$, Ciro o Moisés. Tanto la

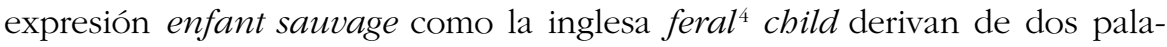
bras latinas silva (bosque) y ferus (fiero). Aunque, como indica Lucienne Strivay (2006), la realidad a la que hacen referencia esta combinación de palabras precede a las mismas. Los casos más antiguos registrados hablan simplemente de monstruos.

La tradición narrativa en la que se insertan los relatos sobre niños mantenidos deliberadamente ${ }^{5}$ confinados e incomunicados, y aquella otra que atribuye a algunas personas características excepcionales por haber sido nutridos con la leche de animales salvajes, haber cohabitado con ellos -o, simplemente, compartido el mismo nicho ecológico tras su abandono-, presentan la misma ambigüedad que se encuentra también en las historias de sus más cercanos parientes mitológicos: los homines silvatici.

Éstos fueron clasificados así más por su perturbador roce con los límites de la sociabilidad que por los modos por los que esa frontera era alcanzada, como nos ha enseñado Roger Bartra con sus trabajos ${ }^{6}$. Tan hom-

\footnotetext{
${ }^{3}$ La fortaleza y valor de estas figuras míticas vendrían realzadas por su carácter híbrido animal y humano, pues serían alimentadas por la sangre batida hasta volverse blanca de sus madres adoptivas — pues así era pensada la leche en la fisiología clásica-, completando así una ingesta de sangre que comenzó en el embarazo y que iría poco a poco modelando sus cuerpos. La leche materna es un "fluido cultural" que transmite la moralidad de la nodriza; en este caso les sería transmitida, por el contrario, la animalidad y la fiereza.

${ }^{4} \mathrm{El}$ adjetivo feral aparece en inglés a comienzos del siglo XVII, por influencia francesa.

5 Al menos tiene que haber otra persona que conozca el encierro y lo consienta, porque en estos casos el niño no puede alimentarse por sí mismo.

${ }^{6}$ Sobre este tema destacan los siguientes libros y artículos de este autor: 1991. "Identity and Wilderness. Etnography and the History of an Imaginary Primitive Group". Ethnologia Europaea 21 (2): 103-125; 1992. El salvaje ante el espejo. México; 1993. "Salvajismo, ci-
} 
bre salvaje es el eremita tentado en el desierto como el bruto, heredero de los sátiros, cubierto de un pelaje hirsuto, señor de las bestias. Ambos formaban parte de aquellas criaturas que habían sido creadas por Dios para monstrare, para enseñar a los hombres su poder absoluto sobre los cuerpos vivos o muertos.

Antes de descubrirse en América la existencia de pueblos enteros sumidos en la amoralidad de la vida sin Dios, los homines silvatici eran fundamentalmente especímenes aislados cuyos pecados los habrían arrastrado a un proceso de involución. De este modo, estos individuos habrían devenido en salvajes como consecuencia de sus actos, o de sus circunstancias.

[Habían] caído en la condición bestial debido a la locura, al hecho de haber crecido entre animales, a la soledad o a las extremas penalidades sufridas. La iconografía los muestra velludos, feroces, incontinentes, cubiertos con pieles, señores de los bosques, aunque también de los desiertos, y en general de los parajes extremos, donde la civilitas es imposible. Para muchos pensadores, no había un ser salvaje, sino una existencia silvestre: un peligro de derrumbe del hombre a un estado eventualmente pasajero y, en todo caso, no innato (Bartra 1992: 89).

Aun así existe una numerosa iconografía desplegada en tapices, relieves de edificios y objetos de uso doméstico, que los representa también viviendo en sociedad de iguales, alimentando a sus hijos o arando sus tierras; atacando conjuntamente castillos moros u obligados a danzar en las fiestas de los nobles un baile especial que lleva su nombre. Al igual que las hordas de perros pueden mostrarse más feroces que manadas de lobos, sin que eso cambie la domesticidad de su especie, existían avatares históricos — pestes, guerras, catástrofes naturales, etc.- que podían producir en los colectivos el mismo marasmo y posterior caída en la decadencia moral que en los individuos.

No sería hasta el siglo XV cuando, en las lenguas romances, comienza a generalizarse el sustantivo común plural salvajes — exportado desde los países mediterráneos-, para ser aplicado a otra categoría de personas: los indios. El uso de la palabra sauvage utilizada como sinónimo de wild man se encuentra por primera vez en inglés en un texto del año 1588, y aún en la Enciclopédie ilustrada (1751-1765), se distingue de manera muy clara entre el nombre singular — que se asocia en el lenguaje médico a las plantas que crecen espontáneamente en los campos y, por extensión, a los animales no domésticos-, del plural que designa a los pueblos bárbaros que viven sin leyes, sin policía, sin religión y sin habitación fija, y que son así llamados porque viven comúnmente en la selva. En concreto se denomina así a to-

vilización y modernidad: la etnografía frente al mito". Alteridades 3 (5): 35-50 y 1997. El salvaje artificial. Barcelona: Destino. También fue el comisario de una exposición titulada El salvaje europeo, en el Centre de Cultura Contemporània de Barcelona en 2004. 
dos los pueblos indios "que no viven bajo el yugo de ningún país y se mantienen aislados". Al contrario que en el caso de los homines silvatici, su salvajismo no sería una consecuencia sino una causa, un motor primero.

Pero del mismo modo la palabra salvajes pasó a denominar a las sociedades indígenas americanas:

La palabra Indias no tardó en convertirse en un término para describir cualquier entorno en el que los hombres vivían en la ignorancia de la fe cristiana y de los modos apropiados de la vida humana. Los misioneros jesuitas hablaban constantemente de esas Indias de Asturias, Calabria, Sicilia y del Abruzzi, regiones donde, según decían, las gentes vivían como salvajes polígamos y, aparentemente, politeístas. [...] [Alonso de la Veracruz afirmaba que] el indio era una especie inferior de hombre, que su estilo de vida, como el de los campesinos españoles, se debía al hecho de que no vivían en una verdadera politia. Una vez que les reunía en agrupaciones políticas y se les albergaba en ciudades, su capacidad innata para gobernarse a sí mismos aparecía inmediatamente. En otras palabras, las mentes de los hombres estaban casi completamente determinadas por el entorno en que vivían. Pero el campesino que vivía "con las bestias" fuera de las murallas de la ciudad también era, como todas las masas de campesinos pobres, una parte necesaria del plan de Dios para la humanidad (Pagden 1988: 139-140).

Así que en algunos lugares escondidos en el interior de Europa nacían y vivían también estos seres, inferiores jerárquicos de un estamento que "bien poco se diferenciaba de los brutos animales", en palabras de Vitoria, ya que para las gentes de las ciudades, los campesinos y los indios compartían una misma existencia brutal.

La imaginación popular especulaba con la posibilidad de que estas criaturas salvajes fueran seres híbridos, fruto de acoplamientos truculentos entre hombres y animales, cuya imperfección los habría convertido en infértiles como los mulos; o bien que, dado un caldo de cultivo apropiado, nacieran de generación espontánea, como se creía que ocurría con los insectos o reptiles, algo no tan alejado de la teología popular mostrada en el libro de Ginzburg El queso y los gusanos. A principios del siglo XVII la condición híbrida de los niños bravíos quedaba recogida en los nombres que señalaban el tipo de aberración que los ha generado: wolf-boy, bear-boy, enfantmouton, etc.

Los pequeños muchachos solitarios serían vistos todavía en estos momentos - como lo fueron los homines silvatici a los que sustituyen-, los representantes de una raza o un tipo bumano, idea que culminaría con la clasificación de Linneo ${ }^{7}$. Como se pensaba que las criaturas habían sido creadas por Dios de modo inalterable, existía la necesidad de generalizar bajo

\footnotetext{
${ }^{7}$ Es muy significativo que casi independientemente de la edad estimada de la persona encontrada en "situación de salvajismo" se la considere en la niñez.
} 
el nombre homo ferus lo que anteriormente no era más que una lista de casos particulares.

Estos seres fueron clasificados a partir de un nombre latino que incluía una referencia al animal con el que se le relacionaba, a su sexo y al lugar donde fue encontrado, y descritos como criaturas que andan a cuatro patas, son mudos y tienen abundante pelo. La jerarquía utilizada en el Sistema Naturae (1738) de Linneo se basaba sobre todo en las características físicas externas de los sujetos. Su clasificación sufrió ligeras variaciones en las distintas ediciones (Douthwaite 1997). En la décima (1758) el género bomo aparece dividido en cuatro niveles: homo diurnus, que vendría a ser el homo sapiens; el bomo nocturnus, que agruparía básicamente a los chimpancés y orangutanes; homo monstruosus, como los hotentotes o los gigantes de la Patagonia, y homo ferus, de los cuales se habían identificado seis casos como el Juvenis lupinis hessensis o niño lobo de Hesse y el Juvenis Hannoveranus o Peter de Hannover. La edición de 1766 incluye en esta categoría también a la Puella Campanica. Las referencias a los individuos desaparecerían en la siguiente edición (1788) en la que ya se los denomina genéricamente bomines feri, con las características reseñadas más arriba.

En el siglo XVII ocurre también otro cambio notorio en el tratamiento de estas criaturas: comienzan a ser conocidas por su nombre de pila, lo que indica la generalización de su bautismo a la vez que una "confirmación humana por la palabra" (Strivay 2006: 35).

\section{ESPECULACIONES SOBRE EL INTERÉS TEÓRICO DE LOS NIÑOS SALVAJES}

La definición clásica de niño salvaje resulta bastante problemática al ser trasladada a cualquier otra tradición cultural distinta a la que la vio nacer, y la convivencia entre humanos y animales ha sido siempre puesta en cuarentena cuando ha salido de labios nativos.

Podría ser quizás imprudente asegurar que es imposible que los niños puedan ser amamantados por bestias salvajes — diría Tylor-, aunque el hecho de que la loba empuje a sus lobeznos a valerse por sí mismos antes de un año no es muy compatible con la noción de que la criatura es un prisionero ${ }^{8}$ de su familia durante varios años; podemos solamente decir que es muy improbable y sólo puede ser creído con la mayor de las evidencias; pero si todos los asiáticos vinieran a declarar al unísono que un niño y un cocodrilo han nacido gemelos en un único parto, yo no lo creería (Tylor 1863: 31).

\footnotetext{
${ }^{8}$ Tylor utiliza la palabra inmate que se utiliza sobre todo para denominar a las personas que son mantenidas en prisión o internadas en un sanatorio psiquiátrico.
} 
La extensa literatura folclórica al respecto y los relatos del capitán Cook y Sir Joseph Banks — que tuvieron la oportunidad de comprobar lo arraigado de esta creencia, muy extendida en todo el sudeste asiático-, le indicaban al antropólogo el poco crédito que se podía dar a los testimonios orientales sobre los niños-lobo. A pesar de ello casi el 30\% de los hallazgos reconocidos han sido encontrados en la India?.

En su artículo "Wild men and beast-child", Tylor concluye que incluso los casos plenamente autentificados de "seres que han sido hallados viviendo en un estado menos avanzado que las tribus más primitivas", son de escaso valor para la antropología. Antes que él otros, como Blumenbach, habían llegado a una conclusión parecida. Estas criaturas podrían tener su interés quizás para experimentar nuevos métodos pedagógicos o psiquiátricos, pero poco se podría aprender de ellas que revelara dónde está el límite inferior del salvajismo, pues incluso las tribus australianas y los isleños de Andaman, que eran reconocidos como los más primitivos del mundo, conocían el fuego, tenían habla articulada y utilizaban herramientas. "Los hombres originarios, como el poeta los describe, vagando, una horda miserable y muda a través de los bosques, no existen sobre la Tierra." Sólo se puede llegar a ellos a través de la especulación, tomando como modelo la mente infantil poco desarrollada y el aprendizaje de los ciegos, sordos y mudos, cuyos defectos físicos "les han obligado a formar sus opiniones a partir de la evidencia directa de sus sentidos, sin el tesoro de conocimientos que ha sido acumulado por las edades anteriores y que los niños ordinarios adquieren casi inconscientemente".

De este modo deslegitimaba el más autorizado estudio llevado a cabo hasta ese momento: el de Itard, si bien coincidía con él en la opinión de que cualquier sociedad, independientemente de su grado de barbarie educa a sus hijos según sus costumbres, y que por lo tanto no existen las ideas innatas. La diferencia fundamental entre los planteamientos de Itard y de Tylor se encuentra en la consideración del estado mental de estos niños bravíos. El fracaso del médico francés convenció a sus sucesores de que eran idiotas congénitos. Los pequeños sufrían una enfermedad provocada por la crueldad de su situación anterior: la dementia ex separatione (según Rauber, 1888) —inspirada en el caso de Kaspar Hauser, según la cual la perturbación mental sería causada por el aislamiento-, o la isolatione amentia (se-

\footnotetext{
${ }^{9}$ De las interpretaciones no europeas de estos encuentros sólo conozco algunas interesantes anotaciones en el diario del reverendo Singh, que asistió a la captura de Amala y Kamala en 1920 y las entrevistas de Ogburn —que coincide plenamente con el espíritu incrédulo de Tylor-, tendentes a desenmascarar el falso niño-lobo de Agra (1957), y en general, la existencia misma de este fenómeno.
} 
gún Tregold, 1920), enfermedad que compartían los sordomudos. Una persona privada de razón no podría nunca ser modelo de la evolución humana.

Pero, en su Memoria acerca de los progresos de Victor de l'Aveyron (1801), Itard sí creía posible encontrar en su desarrollo las respuestas que dieran la clave sobre la humanidad originaria y, si hasta el momento no se habían hallado en otros, había sido debido simplemente a la torpeza de los métodos empleados.

Será preciso, por lo tanto, buscar en otra parte la figura del verdadero hombre bravío, del que nada ha tomado de sus semejantes: habría que trazarla sobre los historiales singulares de los pocos individuos que a lo largo del siglo XVII fueron hallados por los bosques, llevando una existencia solitaria, a la que desde su más temprana edad habrían sido abandonados. Pero tan torpemente procedía en aquellos tiempos el estudio de las ciencias, entregadas al afán de las explicaciones, al azar de las hipótesis y a las especulaciones de gabinete, siendo tenida en nada la experiencia, que aquellos hechos de valor inestimable para la historia natural del hombre hubieron de perderse para siempre (Itard 1801/1982: 8).

El tema es replanteado por Zingg en 1939. Este antropólogo de la Universidad de Denver anima al reverendo Singh a que publique su diario con las observaciones hechas a Amala y Kamala —encontradas viviendo entre lobos en 1920-, consciente de que parte del escepticismo de sus colegas se debía a la incredulidad y que era necesario procurar un estatuto científico al estudio del hombre salvaje. Dada la naturaleza de los problemas a los que estos seres parecían poder aportar alguna luz, la fina línea entre folclore e historia resultaba especialmente importante de dilucidar, pues sólo la certeza histórica podía servir de base firme para construir el conocimiento científico. El diario de Singh es reproducido — como parte de una extensa monografía de Zingg, que pasa revista a los 35 casos reconocidos hasta el momento- acompañado de varios prefacios y postfacios de testigos y especialistas en psicología del desarrollo (entre ellos Gesell, que escribiría poco después su propio libro sobre el caso de las niñas lobo), y de un atestado del juez del distrito de Midnapore, que avala la veracidad de los documentos y de las afirmaciones del reverendo puesto que "sin ninguna duda, su buena fe merece confianza absoluta". Wolf-children and feral man servirá a partir de entonces de punto de referencia obligado para estos estudios.

Cada uno de los participantes en este volumen colectivo tenía, no obstante, sus propios intereses. Singh y sus hermanos en la fe prestaban mayor atención a la evolución moral de las criaturas, en la búsqueda de una respuesta al problema teológico del pecado original; mientras que Zingg se afanaba en despejar los límites disciplinarios entre la psicología, la sociología y la antropología. Si la psicología estudia al hombre como "un conjunto de variables entre las cuales el entorno es una constante, mientras que la 
sociología se ocupa de las variables del entorno social y asimila al individuo como una constante", la antropología estudiaría "el corpus de esquemas comportamentales humanos transmitido por el mecanismo social. Son precisamente estos esquemas comportamentales los que están ausentes en los hombres salvajes." (Zingg 1980: 156-158)

El argumento de Zingg se basaba en que los individuos criados entre animales —de hecho, los únicos realmente individuales junto con locos y reclusos ${ }^{10}$ — son seres psicológicamente capaces, puesto que si fueran criaturas anormales no habrían podido sobrevivir en condiciones tan duras; que han sido de algún modo socializados, ya que han aprendido algunas pautas de conducta, pero que su socialización no ha sido "humana", puesto que carecen de los rudimentos culturales que solamente pueden ser transmitidos a través de la convivencia con otros seres humanos. Es decir, han sido sometidos a un proceso de aprendizaje, pero no de aculturación. Los niños-lobos han aprendido a actuar como lobos al igual que la niña-gallina de Tabua (Portugal) ${ }^{11}$ — mantenida en un gallinero durante ocho años alimentándose de maíz, berzas cortadas y café-, mostraba "semejanzas flagrantes con las gallináceas", en opinión de los médicos que la trataron, tanto en su fisonomía: perfil, posición labial, dentición formada como si fuera un pico y posición constante de los brazos idéntica a las alas de las gallinas, como en su comportamiento (por ejemplo, defecaba en cualquier sitio y se comía sus propias heces).

Tinland (1968) acuñaría la palabra ensauvagement para referirse a este proceso "que sugiere que los niños salvajes e incluso los niños sin más se vuelven salvajes (ensauvagés); el salvajismo y asilvestramiento de los niños no es una cualidad o una condición, sino el resultado de un proceso y un cúmulo de circunstancias".

Las conclusiones de Zingg no se alejan tampoco mucho de las formuladas, años más tarde, por Deleuze y Guattari.

Por supuesto no se trata de una producción real, como si el niño hubiera "devenido" realmente animal; tampoco se trata de una semejanza, como si el niño hubiese imitado a animales que le habrían realmente criado; tampoco se trata de una metáfora simbólica, como si el niño autista, abandonado o perdido, solo hubiese devenido el "análogo" de un animal. Schérer y Hocquenghem tienen razón cuando denuncian ese falso razonamiento basado en un culturalismo o un

10 "El individuo que se aparta demasiado del patrón de estos roles, es sacado de circulación y se lo aísla en la intimidad de prisiones o asilos, las moradas de los auténticos individuos" (Zingg 1982: II, 576).

${ }^{11}$ Isabel Quaresma nació en 1970. Su madre la encerró en el gallinero para poder ir libremente a trabajar a los campos de labranza en cuanto la niña comenzó a andar. Fue llevada al hospital de Tabua por una organización religiosa en 1980. 
moralismo que invocan la irreductibilidad del orden humano: pues el niño no se ha transformado en animal, solo mantendría una relación metafórica con él, inducida por su debilidad o su rechazo. Por su cuenta, ellos invocan una zona objetiva de indeterminación o de incertidumbre, "algo común e indiscernible", un entorno que hace que resulte imposible decir por dónde pasa la frontera entre lo animal y lo humano, no sólo entre los niños autistas, sino en todos los niños, como si, independientemente de la evolución que le empuja hacia el adulto, hubiese en el niño espacio para otros devenires, "otras posibilidades contemporáneas" que no son regresiones sino involuciones creadoras, y que hablan "de una inhumanidad vivida inmediatamente en el cuerpo como tal" bodas contra natura. Realidad del devenir animal sin que uno devenga en animal en realidad. En ese caso, de nada sirve objetar que el niño-perro sólo hace el perro en los límites de su constitución formal, y lo que hace de canino es algo que otro ser humano hubiera podido hacer si hubiera querido. Pues lo que hay que explicar es que precisamente todos los niños, e incluso muchos adultos, lo hacen más o menos, muestran una connivencia inhumana con el animal más bien que una comunidad simbólica edípica. Tampoco hay que pensar que los niños que comen hierba, o que comen tierra o carne cruda, sólo obtienen vitaminas o elementos de los que su organismo carecería. Se trata de hacer cuerpo con el animal, un cuerpo sin órganos definido por zonas de intensidad o de entorno (Deleuze y Guattari 1988: 274-276).

En 1949 Lévi-Strauss también se vio obligado a pronunciarse sobre la pertinencia de utilizar a estos seres para pensar en los límites de la condición humana, y lo hizo en el capítulo llamado "Naturaleza y cultura", con el que se inician Las estructuras elementales del parentesco ${ }^{12}$. Para él —como para Tylor-, el supuesto salvajismo que se les atribuía a estos niños no era más que idiotez congénita, causa inicial de su abandono. Se trataba, pues, de niños de desecho, "monstruosidades culturales" producidas por el azar o la experimentación. Era imposible buscar en ellos los vestigios del hombre natural, al contrario que en los animales domesticados que

si se encuentran perdidos o aislados, vuelven a un comportamiento natural que fue el de la especie antes de la intervención externa de la domesticación. Pero nada semejante puede ocurrir con el hombre, ya que en su caso no existe comportamiento natural de la especie al que el individuo aislado pueda volver por regresión. Como más o menos decía Voltaire: una abeja extraviada lejos de su colmena e incapaz de encontrarla es una abeja perdida; pero no por eso, y en ninguna circunstancia, se ha transformado en una abeja más salvaje ${ }^{13}$.

12 "Tres o cuatro páginas no muy útiles y cuya solución no agrega gran cosa a la demostración", como se verá obligado a decir en el prólogo a la segunda edición, tras las críticas de Lucien Malson, sobre su falta de rigurosidad en el uso de las fuentes.

${ }^{13}$ C. Lévi-Strauss (1985: I, 37-38). La reflexión de Lévi-Strauss se basa muy directamente en la de Blumenbach al que lee de la edición inglesa de su obra Anthropological Treatises of J. F. Blumenbach, Londres, 1865. La cita de Voltaire, que también se encuentra en el trabajo de Blumenbach, está sacada del Ensayo sobre las costumbres (1756). 
En último término, la oposición naturaleza-cultura suponía el rejuvenecimiento del dilema estado de naturaleza-estado de sociedad que tanta tinta hizo correr en los siglos XVII y XVIII y que es al que se refiere concretamente la cita de Voltaire: "Si encontrásemos una abeja perdida ¿deberíamos concluir que esta abeja está en estado de pura naturaleza, y que aquellas que trabajan en sociedad en la colmena habrían degenerado?"

La Declaración de los Derechos del Hombre del buen pueblo de Virginia (1776) hacía en este sentido una distinción que no fue reconocida en el homónimo código francés: "Que todos los hombres son por naturaleza igualmente libres e independientes y tienen ciertos derechos innatos, de los que, cuando entran en estado de sociedad, no pueden privar o desposeer a su posteridad por ningún pacto”.

La pesquisa sobre el estado de naturaleza —en palabras de Hobbes, una existencia puramente individual en la que la sociedad ha desaparecido; en la que los hombres "viven sin otra seguridad que no sea la que les procura su propia fuerza", en un "constante miedo, y un constante peligro de perecer con muerte violenta. Y la vida del hombre es solitaria, pobre, desagradable, brutal y corta" (Hobbes 1651/1989: 108) — se encuentra implícita en las reflexiones de los pedagogos y filósofos que se interesaron por los niños salvajes entre los siglos XVII y comienzos del XIX. Cuando Hobbes escribe su Leviatán, hace ya algunos años que ha sido encontrado Juan de Lieja (1630) y se conoce desde antiguo la existencia constatada de otros tres niños-lobo (el de Hesse, 1341; el de Wetterau, 1344, y el de Ardenne, cerca de 1500) y uno en Dinamarca alimentado por una osa (aprox. 1600).

Estas criaturas, evidentemente disminuidas, sin impulsos sexuales, que se desplazan a cuatro patas y son incapaces de comunicarse de modo civilizado ¿son seres naturales? O, dicho de otro modo, ¿ha sido el aislamiento el que ha provocado en ellos la caída en el abismo del salvajismo, o se trataba en origen de individuos deficientes y la naturaleza sólo se ha encargado de conservar un legado imperfecto? ¿Es la vida en sociedad la responsable de hacer hombre a un recién nacido o su humanidad existe independientemente de esta vida social?

Podríamos continuar la historia de la fortuna crítica — por hablar en términos literarios- de las teorías sobre niños salvajes siguiendo de algún modo los avatares metafóricos de la abeja, tan utilizada en el tiempo para hablar de la comunidad de los hombres, y en especial la disputa entre tradición y modernidad. Una reciente publicación de Bartra recupera la oposición antigua entre ella y la araña y con ello su figura nómada, vagabunda, que busca fuera de su comunidad la respuesta a las preguntas que la araña contesta a partir de su propia reinterpretación. "El problema — dirá Bartra— es que si aún no está en ruinas su colmena, la abeja que regresa eventual- 
mente para realizar la célebre danza con que solía comunicar a sus semejantes lo que había descubierto, ya no es entendida. Y su zumbido a veces también pierde sentido en el nuevo hábitat" (Bartra 2004: 22).

Es curioso constatar en el reiterado recurso de la incomunicación fallida de la abeja, por pérdida de sintonía social, algo semejante a lo que ocurre con los niños salvajes. Si hallaron en su camino hacia la soledad extrema experiencias de las que se pueda sacar una ventaja adaptativa, éstas son claramente incomunicables y abocadas al callejón sin salida de la excepcionalidad. Con el paso del tiempo, las respuestas a la pregunta de Voltaire han ido dando un giro de 180 grados y la abeja perdida ha ido poco a poco degenerándose mientras se apartaba de la sociedad natural de la colmena. El hombre - diría Levi-Strauss, siguiendo de nuevo a Blumenbach- es el único animal que se domestica a sí mismo. Por lo tanto si hay taras en este proceso de domesticación serán motivadas, bien por problemas físicos de los individuos o bien por causas netamente culturales.

\section{EL SALVAJISMO DE LA CULTURA}

El estudio de los niños salvajes y en especial el de Kamala, devenida animal y posteriormente resocializada, serviría también de modelo extremo de un fenómeno que puede ser provocado culturalmente. En el último capítulo de su monografía sobre los huicholes, Zingg desarrolló los conceptos de "cultura genuina" — que es armoniosa y equilibrada- y "espuria" que es aquella que frustra y anula a sus individuos convirtiéndolos en dementes. Estas "culturas espurias" generarían sujetos con características y condiciones morales semejantes a los niños salvajes, como intenta mostrar a partir de los ejemplos que aporta, llegando a hablar de "culturas psicopatológicas", que serían aquellas con un deterioro tan avanzado que podría decirse que carecen de cultura propia:

Pero más sorprendente aún que vivir dentro de una cultura psicopatológica es vivir sin ninguna cultura. Esto significa que toda creencia, pensamiento y acción establecidos por la costumbre y toda la herencia del pasado, están tan desacreditados, tan quebrados y desarticulados, que el individuo no encuentra ningún esquema sólido y aceptable de pensamiento y acción en el cual poder confiar. Se le deja librado a sus propias fuerzas y recursos para crear su particular mundo a partir del caos, tarea en la que está completamente solo (Zingg 1982: II, 579-580).

Se debe a Bettelheim uno de los más relevantes estudios sobre el autismo infantil: La fortaleza vacía (1967), en el que especula con la idea de que estas criaturas perdidas son en realidad autistas, cuya conducta no revela una inmersión en la vida silvestre sino los síntomas de una enfermedad que 
actúa como mecanismo de defensa para poder soportar una existencia hostil. En este libro introduce la siguiente distinción terminológica: la expresión generalizada niño salvaje, que designa a aquel que habría sido criado por animales, debe pasar a referirse al sujeto que manifieste comportamientos salvajes (wild) y que son relativamente frecuentes en este campo clínico. En cambio, reserva el término ferales para aquellos niños de los cuales se dice —afirmación que rechaza Bettelheim — que fueron criados por animales.

¿Por qué se cree, sin embargo, que éstos son niños ferales, o más concretamente, niños lobos?

Tres factores promovieron esta creencia. En primer lugar, muchos de estos niños no hablan, si bien no son mudos. La palabra es lo que principalmente distingue al hombre del animal. El hombre no puede hablar, y entonces estos niños coinciden en algo con ellos. En segundo lugar, todos los niños, incluso los débiles mentales, tienen necesidad de cuidados humanos y buscan además su contacto; pero estos evitan la compañía humana. Y tercero, sucede que estos niños son de gran ferocidad en sus ataques, utilizan las uñas y los dientes como los animales. Fuera de estas causas, no se me ocurren más especulaciones. [...]

El origen del comportamiento subhumano y animal de estos niños [se refiere ahora a sus pacientes] ya no lo buscamos, en nuestros tiempos ilustrados, en el mundo de los espíritus, sino en su condicionamiento y en su medio [...] Normalmente, remitimos el comportamiento autista a un extremo aislamiento afectivo sufrido muy precozmente, a la manera inhumana como se les trató o a otros traumas específicos o inespecíficos sufridos anteriormente. Pero, en el primer encuentro con su salvajismo, y después, ante su retirada total, su obstinación y violencia, sentimos a veces que también nosotros nos remitimos a la idea de que están poseídos y de que son animales.

Citaremos otra reacción típica de un comportamiento corriente de Ana: "Mientras la observaba aplicándose saliva a todas las partes de su cuerpo, morderse y magullarse los dedos de los pies, me daba toda la impresión de un animal aseándose de forma destructiva." Por consiguiente, si la simple observación de estos niños lleva de forma natural a pensar que "son (como) animales", entonces la solución más fácil del problema planteado por su comportamiento es creer que éste se debe al hecho de haber sido criados de forma animal; y que tienen que haber sido reducidos a ese comportamiento animal por haber vivido, forzosamente, con animales (Bettelheim 1967: 447-449) ${ }^{14}$.

Y es que, en los años treinta del pasado siglo, los intelectuales empezaron a tomar conciencia de que la verdadera barbarie se encontraba en el seno de la civilización occidental —la más violenta de las "culturas espurias"- y no sólo el autismo, sino también la esquizofrenia, empiezan a reconocerse como "enfermedades culturales". En "Cultural Isolation and the Schizophrenic Personality”, Faris (1934) mantuvo por primera vez la hipóte-

\footnotetext{
${ }^{14}$ Véase también Bettelheim (1959).
} 
sis de que la causa de la esquizofrenia era el aislamiento social de la persona. La enfermedad sería una herramienta del espíritu para luchar contra la imposibilidad de establecer relaciones sociales gratificantes, normalmente por motivos que escapan a su control.

Esta orientación supone un progresivo desvío del interés por el enfrentamiento con las fuerzas de la naturaleza para enfocarlo hacia la lucha del hombre, solo y aislado, contra la sociedad. La transformación de estos pequeños en "enfermos culturales" culpabiliza de su existencia a los encargados directos de su cuidado, primero, y a la sociedad entera, después.

\section{EXPERIMENTOS PROHIBIDOS}

Desde los años sesenta han proliferado los casos de niños encontrados en situación de aislamiento, como se puede ver en la página web http:// www.feralchildren.com ${ }^{15}$, verdadero observatorio del estado de la cuestión sobre los niños salvajes, con su rastreo a nivel mundial de cualquier evidencia de un nuevo encuentro. Esta web duplica el número de los recogidos en el primer intento de sistematización llevado a cabo por Lucien Malson en 1964, que había registrado 53 casos hasta 1961, irregularmente documentados pero normalmente admitidos como históricos ${ }^{16}$. Este enorme aumento en las cifras (actualmente registra 133) no es debido al mayor número de niños abandonados en los últimos cuarenta años, sino a la necesidad de los mismos para contrastar hipótesis. En otro orden de cosas, es una consecuencia del mayor interés por parte de los servicios sociales que intervienen en los casos de socialización anómala y de la eficacia de los medios de comunicación, ávidos de noticias.

En los estudios que estos niños han provocado y en las revisiones de los trabajos clásicos que se han producido últimamente aparece una y otra vez la expresión "experimento prohibido" (forbidden experiment). El significado de estas palabras queda explicado en esta entrevista, realizada a la lingüista Elissa Newport para el documental Secret of the Wild Child, dedicado al descubrimiento de Genie.

\footnotetext{
${ }^{15}$ Andrew Ward es su webmaster. Los datos se encuentran ordenados cronológicamente desde el primer hallazgo "histórico" en el año 250 (registrado en la Guerra gótica de Procopio de Cesarea) hasta el 2008. No contempla en ella aquellos casos que podrían denominarse "mitológicos" (Zeus, Rómulo y Remo, Ciro, Moisés, etc.), aunque sí algunos, como el caso de los niños verdes de Woolpit, bastante poco probables.

${ }^{16}$ En el listado de www.feralchidren.com se registran 23 hallazgos anteriores al año de edición francesa del libro de Malson (edición española de 1973), aunque algunos de ellos son de certeza dudosa.
} 
Lo que Lenneberg proponía es lo que ha sido llamado la "hipótesis del período crítico", y lo que sugería era que hay un período particular en la vida de los humanos en el que están maduros para el aprendizaje de las lenguas. Lo que esta hipótesis estaba buscando era alguna evidencia más directa. Pero, por supuesto, tú no haces esos experimentos. Uno nunca desea privar a alguien del lenguaje durante el período crítico para ver qué pasa. Lo que ocurrió fue que, por aquel entonces, cuando podría haber sido el mejor momento para demostrar la hipótesis de Lenneberg, Genie fue descubierta.

En el caso de Genie, este experimento se llevaría demasiado lejos. Pasó de mano en mano, de investigador en investigador, sufriendo todo tipo de abusos hasta que fue recluida en un hospital donde sus pequeños progresos intelectuales sufrieron una drástica regresión. Harlan Lane, el principal especialista en Víctor de L’Aveyron, daba su opinión al respecto en el mismo documental.

¿Qué podemos sacar en claro de esta historia realmente triste? Mira, hay un dilema ético en este tipo de investigación. Si tú quieres hacer ciencia rigurosa, entonces los intereses de Genie pasan a un segundo plano. Si tú solamente te preocupas de ayudar a Genie, entonces no podrías hacer la mayor parte de las investigaciones científicas. Entonces ¿qué vas a hacer? Para poner las cosas peor los dos roles, el del científico y el del terapeuta, estaban en su caso combinados en una misma persona. Así que yo pienso que futuras generaciones estudiarán el caso de Genie, igual que ha sido estudiado el de Víctor, no solamente en lo que nos puede enseñar sobre el desarrollo humano, sino también en lo que puede enseñarnos sobre las recompensas y los riesgos de llevar a cabo "el experimento prohibido".

Este dilema ético de aquellos que han trabajado directamente con las personas reales que han pasado por una experiencia que los ha convertido en niños salvajes se complementa en el presente con la investigación de otro problema igualmente complejo: las relaciones entre descubridor-investigador y descubierto-investigado reproducen unas similares relaciones entre todo adulto y todo niño. Siguiendo a Norbert Elias, Benzaquén (1999) propone que la diferencia entre estas dos edades de la vida es la confrontación entre un grupo civilizado y otro que no lo está.

En circunstancias normales, el estado incivilizado del niño no dura mucho porque "en nuestra sociedad cada ser humano es expuesto desde el primer momento de su vida a la influencia y la intervención moldeadora de los crecimientos civilizados". En circunstancias anormales, cuando el estado incivilizado del niño se prolonga más allá de lo que la sociedad considera aceptable, tenemos un niño salvaje.

Descubrimiento y civilización son inextricablemente - tanto literal como metafóricamente- conectados con la infancia en la modernidad. Los niños son asociados con los salvajes como los otros de la civilización, tanto como punto de parti- 
da y, más aún, como esos otros que son descubiertos en y a través de su estado incivilizado. El niño salvaje, en tanto que una fascinante y elusiva figura de la otredad en la cual el "niño" y el "salvaje" son encontrados en un único cuerpo, ilumina la transformación (en el sujeto adulto) y el incremento de la distancia (entre el adulto civilizado y el todavía-no-civilizado niño) (Benzaquén 1999: 471-472) ${ }^{17}$.

Si esto es así, “cómo se pueden conciliar las demandas contrapuestas de, por un lado, acercarnos al niño como a otro sujeto cuya integridad, separación y libertad debería ser respetada, y por otro lado, cuidar al pequeño, intervenir, interferir, educar, moldear, cambiar?" (Benzaquén 1999: 481). Esta cuestión permea en los países democráticos toda la delicada interacción entre el adulto y la persona que crece y, por otro lado, toda investigación en antropología aplicada.

\section{BIBLIOGRAFÍA CITADA}

Bartra, R. 1992. El salvaje ante el espejo. México: Era.

Bartra, R. 2004. "Creatividad, territorio y migración", en Grupo de Investigación y Territorialidades, La desgeneralización del mundo. Reflexiones sobre procesos de globalización. Manizales: Universidad de Caldas

Bettlelheim, B. 1959. "Feral Children and Autistic Children". American Journal of Sociology 64 (5): $455-467$.

Bettelheim, B. 1967/1972. La fortaleza vacia: el autismo infantil y el nacimiento del sî mismo. Barcelona: Laia.

Benzaquén, A. S. 1999. Encounters with Wild Children: Childhood, Knowledge and Otherness. Dissertation submitted to the Faculty of Graduate Studies in partial fulfilment of the requeriments for the degree of Doctor en Philosophy. North York, Ontario: York University-UMI.

Deleuze, G. y F. Guattari. 1988. Mil mesetas. Capitalismo y esquizofrenia. Valencia: PreTextos.

Douthwaite, J. V. 1997. "Homo ferus: Between Monster and Model". Eighteenth-Century Life 21 (2): 176-202.

Encyclopédie, ou dictionnaire raisonné des sciences, des arts et des métiers, par une societé de gens de lettres. Tomo V (1755) y VIII (1765). París: Libraires associés.

Faris, R. E. L. 1934. "Cultural Isolation and the Schizophrenic Personality". The American Journal of Sociology 40 (2): 155-164.

Gesell, A. 1941. Wolf Child and Human Child. Nueva York y Londres: Harper and Brothers.

Ginzburg, C. 1981. El queso y los gusanos. Barcelona: Muchnik Editores.

Hobbes, T. 1651/1989. Leviatán. La materia, forma y poder de un Estado eclesiástico y civil. Madrid: Alianza Universidad.

Itard, J. 1801. Memoria acerca de los primeros progresos de Victor de L'Aveyron. En Itard, J. 1982. Víctor de L’Aveyron. Madrid: Alianza Editorial.

\footnotetext{
${ }^{17}$ La cita que reproduce la autora es del libro de Elías The Civilizing of Parents, publicado en 1980.
} 
Lévi-Strauss, C. 1985. Las estructuras elementales del parentesco. Barcelona: PlanetaAgostini.

Linneo, C. 1748. Systema Naturae sistens regna tria Naturae. Estocolmo: Godofredus Kiesewetterus.

Malson, L. 1964. Les enfants sauvages. París: Union Générale d'Editions. [Traducción española: 1973. Los niños selváticos (mito y realidad). Madrid: Alianza]

Ogburn, W. F. 1959. "The Wolf Boy of Agra". The American Journal of Sociology LXIV (5): $449-454$.

Pagden, A. (1988). La caída del hombre natural: los indios americanos y los orígenes de la etnografia comparativa. Madrid: Alianza.

Rauber, A. 1888. Homo Sapiens Ferus oder Die Zustande der Verwilderten und ihre Bedeutung für Wissenschaft Politik und Schule. Leipzig: Zweite Auflage.

Secret of the Wild Child. 1994. Documental de la Public Broadcasting System's Nova. USA.

Strivay, L. 2006. Enfants sauvages. Approches anthropologiques. París: Gallimard.

Tinland, F. 1968. L'Homme sauvage: Homo ferus et Homo sylvestris, de l'animal a l'homme. París: Payot.

Tregold, A. F. 1920 Mental Deficiency. Nueva York: William Wood and Co.

Tylor, E. B. 1863. "Wild men and beast-child". Anthropological review I: 21-32.

Voltaire. 1756/1829. Essai sur les moeurs. Edición electrónica de la Biblioteca Nacional de Francia consultable en www.gallica.com

Zingg, R. M. y J. A. L. Singh. 1980. L'homme en friche. De l'enfant-loup à Kaspar Hauser. Bruxelles: Editions Complexe.

Zingg, R. M. 1982. Los huicholes. Una tribu de artistas. México: Instituto Nacional Indigenista.

Fecha de recepción: 13 de noviembre de 2008

Fecha de aceptación: 17 de febrero de 2009 